\title{
Effect of Temperature on Rice Husk Asing and Its Application on Adsorbing Fe and Zn Metal in Patchouli Oil
}

\author{
Ahmad Said, Is Fatimah, Dwiarso Rubiyanto \\ Program Studi Kimia FMIPA Universitas Islam Indonesia \\ Jalan Kaliurang KM 14,5, Sleman, Yogyakarta, 55584 \\ E-mail: saidchemist20@gmail.com
}

\begin{abstract}
ABSTRAK
Telah dilakukan studi pengaruh temperatur pembuatan adsorben abu sekam padi (ASP) dan aplikasinya pada adsorbsi logam $\mathrm{Fe}$ dan $\mathrm{Zn}$ dalam minyak nilam. Variasi temperatur pengabuan dilakukan pada 300,500 , dan $700^{\circ} \mathrm{C}$ selama 2 jam. Variasi temperatur pengabuan bertujuan mengkarakterisasiadsorben ASP. Karakterisasi yang dilakukan yakni penentuan silika secara gravimetri, diameter pori, morfologi abu dan komposisi unsurdengan teknik SEM/EDS, dan adsorptivitas terhadap metilen biru secara spektrofotometri. Tiga varian ASP diaplikasikan pada pemurnian minyak nilam dengan metode adsorbsi. Rendemen ASP-300, ASP-500, dan ASP-700 yang dihasilkan secara berurutan yaitu 35,4\%, 25\%, dan 16,5\%. Kadar silikanya sebesar 43,12\%, 72,12\% dan 87,7\%. Adsorbtivitas terhadap MB diperoleh 1,1616 mg/g, 0,7507 mg/g, dan 0,4128 mg/g. Diameter pori rata-rata antara 4,4-6,8 $\mu \mathrm{m}$. ASP mampu memurnikan minyak nilam dengan metode adsorbsi. Warna, bobot jenis, indeks bias, dan kadar logam Fe serta Zn pasca adsorbsi telah memenuhi standar mutu minyak nilam SNI. ASP-700 adalah adsorben paling baik dibandingkan ASP-500 dan ASP-300 dalam pemurnian minyak nilam.
\end{abstract}

Kata kunci: temperatur, abu sekam padi, minyak nilam, adsorbsi

\section{ABSTRACT}

Effects of various temperature on rice husk ash (RHA) adsorbent burning and its application on adsorbing $\mathrm{Fe}$ and $\mathrm{Zn}$ metal in patchouli oil have been conducted.Ashing temperature varied at 300, 500 , and $700^{\circ} \mathrm{C}$ for 2 hours. Various ashing temperature aims to characterize RHA adsorbent. These characterizations are determination of silica gravimetrically and its adsorbtivity on methylene blue (MB) spectrophotometrically. Three variants of RHA are applied on patchouli oil purification by adsorbtion method to reduct Fe and Zn metal. Rendement of RHA-300, RHA-500, and RHA-700 resultedsequentlyare $35.4 \%, 25.0 \%$, and $16.5 \%$. Contents of silica are $43.12 \%, 72.12 \%$ and $87.7 \%$. Adsorbtivityon MB yielded as $1.1616 \mathrm{mg} / \mathrm{g}, 0.7507 \mathrm{mg} / \mathrm{g}$, and $0.4128 \mathrm{mg} / \mathrm{g}$. These indicates that RHAis able to purify patchouli oilusing adsorbtion method. Color, spesific gravity, refractive index, andcontentof $\mathrm{Fe}$ and $\mathrm{Zn}$ after adsorbingpass standard of patchouli oil quality as for SNI. Adsorbtivity of RHA-700 on Fe metal removal i.e. $0.620219 \mathrm{mg} / \mathrm{g}$ and $0.00637069 \mathrm{mg} / \mathrm{g}$ on Zn metal removal. So, RHA-700 gives maximum result as adsorbentto purify patchouli oil.

Keywords: temperature, rice husk ash, patchouli oil, adsorbtion

\section{Pendahuluan}

Sekam padi merupakan produk Sekam padi dapat dihasilkan sebesar 20-30\% biomassa yang di dunia pertanian menjadi dari total padi yang digiling (Sipahutar, 
2012). Berdasarkan angka sementara GKG tahun 2013, diperkirakan bahwa limbah sekam padi yang dihasilkan pada tahun 2013 sebanyak 14 - 21 juta ton. Sekam padi mengandung beberapa komponen anorganik seperti $\mathrm{K}, \mathrm{Ca}, \mathrm{Cr}, \mathrm{Mn}, \mathrm{Fe}, \mathrm{Ni}, \mathrm{Cu}, \mathrm{Zn}, \mathrm{Sr}, \mathrm{Br}$, As (Omatola, 2009). Menurut Foo dan Hameed (2009), senyawa $\mathrm{SiO}_{2} \cdot \mathrm{H}_{2} \mathrm{O}, \mathrm{Al}_{2} \mathrm{O}_{3}$, $\mathrm{Fe}_{2} \mathrm{O}_{3}, \quad \mathrm{~K}_{2} \mathrm{O}, \quad \mathrm{Na}_{2} \mathrm{O}, \quad \mathrm{CaO}$, dan $\mathrm{MgO}$ ditemukan di dalam sekam padi. Komposisi anorganik dalam sekam padi sangat bergantung pada kondisi geografis, tipe padi, proporsi area irigasi, zat kimia dalam tanah, waktu panen, dan tipe pupuk yang digunakan (Foo dan Hameed, 2009). Komponenkomponen organik di dalam sekam padi terdiri dari selulosa, hemiselulosa, dan lignin.

Sekam padi mengandung abu sekitar $20 \%$ bobotnya. Abu sekam padi memiliki kemampuan sebagai adsorben dalam dunia pengolahan bahan-bahan pencemaran lingkungan (Foo dan Hameed, 2009). Sebagai adsorben, abu sekam padi baru digunakan secara nyata sejak awal tahun 2000. Abu sekam padi telah digunakan untuk mengurangi konsentrasi bahan pencemar lingkungan, senyawa fenol, pewarna metilen biru, logam - logam berat seperti timbal, seng, kadmium, merkuri, krom, dan nikel.

Sifat fisika dan kimia abu sekam padi juga dipengaruhi oleh suhu pembakaran pembuatan abu sekam padi (Nakbanpote et al., 2000). Dari suhu pembakaran $300-500^{\circ} \mathrm{C}$, menurut Nakbanpote et al (2000), diameter pori rata-rata, volume pori total, dan luas permukaan BET abu sekam padi mengalami peningkatan. Abu sekam padi yang dinyatakan tidak terkontaminasi mengandung silika $\left(\mathrm{SiO}_{2}\right)$ hingga 95\%. Sifat fisika ini dapat digunakan untuk proses adsorpsi. Oleh karena itu, dalam penelitian ini dilakukan variasi temperatur pembakaran pembuatan abu sekam padi pada 300,500 , dan $700^{\circ} \mathrm{C}$ untuk melihat sifat karakteristik paling baik dari dari abu sekam padi.

Dengan memanfaatkan sifatnya yang potensial sebagai adsorben, dalam penelitian ini, abu sekam padi (ASP) dijadikan sebagai adsorben untuk mengikat logam $\mathrm{Fe}$ dan $\mathrm{Zn}$ dalam minyak nilam (Patchouli oil). Kedua logam tersebut merupakan logam pengotor dalam minyak nilam yang dapat menurunkan kualitas minyak nilam. Hal ini mengingat bahwa minyak nilam merupakan minyak atsiri yang masih menjadi sorotan masyarakat karena baunya yang khas yang disebabkan oleh adanya senyawa patchouli alcohol dan norpatchoulenol.

Minyak nilam berwarna kuning muda adalah jenis minyak nilam yang dibutuhkan pasar dunia saat ini, sayangnya masih sukar ditemukan di industri penyulingan minyak 
nilam. Menurutnya, wadah penyulingan dari stainless steel, kaca, ataupun drum bekas dapat mempengaruhi kualitas minyak nilam terutama kandungan logam seperti Fe yang menyebabkan warna minyak nilam menjadi gelap. Kandungan logam Fe dalam minyak nilam akan mempengaruhi produk turunannya yang menjadikannya minyak nilam sebagai bahan utama ataupun campurannya, seperti pada parfum, kosmetik, dan obat-obatan.

Kandungan logam tidak dikehendaki yang tinggi dapat mempengaruhi sifat fisika dan kimia minyak nilam sehingga belum dapat memenuhi standar SNI perdagangan minyak nilam nomor 06-2385-2006. Untuk mengatasi hal ini, pemurnian minyak nilam dapat dilakukan dengan cara adsorpsi logam menggunakan adsorben abu sekam padi. Foo dan Hameed (2009) menyatakan bahwa metode adsorpsidiperhitungkan sebagai metode menjanjikan karena merupakan teknik yang banyak digunakan untuk proses pengolahan limbah, khususnya di negaranegara berkembang ini, efisien dan ekonomis, serta banyak ketersediaannya.

\section{Tujuan Penelitian}

Tujuan penelitian ini adalah sebagai berikut:
1. Untuk mengetahui sifat fisika dan kimia ASP pada variasi temperatur pengabuan.

2. Untuk mengetahui pengaruh ASP bervariasi temperatur pengabuan pada pemurnian minyak nilam melalui penurunan kadar logam Fe dan Zn.

\section{Metode Penelitian}

Penelitian ini membutuhkan bahanbahan seperti: sekam padi, metilen biru (MB), $\mathrm{HNO}_{3}$ p.a., $\mathrm{HCl}$ p.a., $\mathrm{HF}$ p.a., $\mathrm{HClO}_{4}$ p.a., $\mathrm{H}_{2} \mathrm{SO}_{4}$ p.a., akuades, kertas $\mathrm{pH}$ universal, Whatman no. 41.

Alat-alat yang digunakan yakni Spektrofotometer Serapan Atom (SSA) PERKIN-ELMER 5100, Spektrofotometer UV Vis Double Beam U-2010, seperangkat alat gelas dan plastik.

\section{Prosedur Kerja}

\section{A. Preparasi Adsorben ASP}

Sebanyak 100 gram sekam padi dicuci dengan akuades. Kemudian dimasukkan ke dalam oven pada suhu $105^{\circ} \mathrm{C}$ selama 2 jam. Sekam padi tersebut diabukan dengan furnace pada variasi temperatur 300, 500 dan $700^{\circ} \mathrm{C}$ selama 2 jam yang diberikan nama ASP-300, ASP-500, dan ASP-700 secara berurutan. Lalu, ASP didinginkan di dalam desikator. Kadar abu dihitung sebagai 
rendemen abu dari masing-masing suhu pembakaran sekam padi.

\section{B. Karakterisasi Adsorben ASP}

Adsorben ASP diuji kadar silikanya secara gravimetri.Sebanyak 0,5 gram masingmasing ASP-300, ASP-500, dan ASP-700 dilarutkan dengan $10 \mathrm{~mL}$ akuades di dalam gelas piala. Sebanyak $10 \mathrm{~mL} \mathrm{HNO}_{3}$ p.a. dan $20 \mathrm{~mL} \mathrm{HClO}_{4}$ p.a. ditambahkan ke dalam larutan ASP. Larutandengan kondisi tertutup kaca arloji dipanaskan selama 15 menit hingga keluar uap putih. Kemudian larutan didinginkan.

Larutan yang sudah dingin ditambahkan dengan $50 \mathrm{~mL}$ akuades. Larutan dididihkan, lalu disaring dengan Whatman 41. Kertas saring dan residu dicuci dengan air panas 10 kali, lalu diabukan pada suhu $1000^{\circ} \mathrm{C}$ selama 30 menit. Kemudian cawan didinginkan di dalam desikator selama 20 menit. Setelah dingin, cawan berisi residu ditimbang dan dicatat sebagai berat $\mathrm{A}$.

Residu dalam cawan dilarutkan dengan sedikit air dan dipindahkan ke dalam krus teflon, kemudian ditambahkan dengan 1-2 tetes $\mathrm{H}_{2} \mathrm{SO}_{4}$ dan $5 \mathrm{~mL}$ HF. Residu diuapkan sampai kering di atas penangas pasir. Residu dalam krus teflon dipindahkan ke cawan, kemudian dipijarkan di dalam furnace pada suhu $1000^{\circ} \mathrm{C}$ selama 2 menit. Kemudian residu didinginkan di dalam desikator selama 20 menit. Cawan berisi residu ditimbang dan dicatat sebagai berat B.

Kadar silika dihitung dengan Persamaan (1):

Kadar $\mathrm{SiO}_{2}=\frac{A-B}{C} \times 100 \%$

Dimana:

A : berat cawan + residu sebelum proses penambahan $\mathrm{HF}$

B : berat cawan + residu setelah proses penambahan HF

C : berat sampel

\section{Penentuan Serapan ASP terhadap MB (Metilen Biru)}

Sebanyak 0,025 gram ASP-300, ASP500, dan ASP-700 masing-masing dimasukkan ke dalam gelas piala $100 \mathrm{~mL}$ berbeda yang telah berisi $10 \mathrm{~mL}$ larutan $\mathrm{MB}$ 3 ppm. Larutan diatur pada $\mathrm{pH}$ 3, dikocok selama 10 menit. Kemudian larutan disaring dan filtrat diukur absorbansinya pada panjang gelombang maksimum menggunakan spektrofotometer UV-Vis Double Beam (U2010). Banyaknya MB yang teradsorbsi diukur dengan menghitung adsorbtivitasnya (Persamaan (2)).

Adsorbtivitas $=\frac{\text { berat teradsorbsi }(\mathrm{mg})}{\text { berat adsorben }(\mathrm{g})}$ 
D. Karakterisasi Minyak Nilam yang telah diperoleh, dibuat kurva kalibrasi.

\section{Sebelum dan Sesudah Adsorbsi}

Pemurnian minyak nilam dilakukan dengan rasio ASP:minyak nilam $=1: 10$. Minyak nilam yang telah ditambahkan ASP diaduk selama 10 menit pada suhu ruang, lalu disaring dengan kertas bebas abu. Minyak nilam sebelum dan sesudah diadsorbsi dengan 3 jenis ASP dikarakterisasi sifat fisiknya seperti warna, bobot jenis, dan indeks bias sesuai dengan SNI 06-2385-2006, serta sifat kimianya yakni kadar logam Fe dan Zn spektrofotometri serapan atom dengan destruksi campuran kering dan basah.

\section{Persiapan Larutan Standar Fe}

Larutan standar Fe disiapkan dari seri larutan Fe dengan konsentrasi $0 ; 0,5 ; 1 ; 2 ; 3$; 5; dan 10 mg/L. Kemudian absorbansi larutan standar diukur dengan Spektrofotometer Serapan Atom pada panjang gelombang 248,3 $\mathrm{nm}$. Absorbansi yang telah diperoleh, dibuat kurva kalibrasi. Persamaan linier dan koefisien regresinya ditentukan.

\section{Persiapan Larutan Standar Zn}

Pada pengukuran pertama, larutan standar Zn disiapkan dari seri larutan Zn dengan konsentrasi 0; 0,5; 1; 3; dan $5 \mathrm{mg} / \mathrm{L}$. Kemudian absorbansi larutan standar diukur dengan Spektrofotometer Serapan Atom pada panjang gelombang 213,9 nm. Absorbansi
Persamaan linier dan koefisien regresinya ditentukan.

\section{Persiapan Sampel}

Sebanyak 2,5 gram sampel minyak nilam dimasukkan ke dalam cawan. Kemudian cawan dimasukkan ke dalam furnace pada suhu $500^{\circ} \mathrm{C}$ selama 5 jam, lalu didinginkan di dalam desikator. Residu dilarutkan dengan 2,5 $\mathrm{mL}$ aqua regia $\left(\mathrm{HCl}: \mathrm{HNO}_{3}=3: 1\right.$ ), lalu dididihkan hingga volume setengah dari volume awal. Sisa larutan didinginkan, lalu disaring. Filtrat diatur pada $\mathrm{pH} 3$ dengan penambahan $\mathrm{NH}_{4} \mathrm{OH}$, lalu dimasukkan ke dalam labu takar $25 \mathrm{~mL}$ dan diencerkan dengan akuades. Larutan dibuat duplo dan dianalisis konsentrasi logam $\mathrm{Fe}$ dalam minyak nilam dengan Spektrofotometer Serapan Atompada panjang gelombang 248,3 nm dan logam $\mathrm{Zn}$ pada panjang gelombang $213,9 \mathrm{~nm}$.

\section{Pembahasan}

\section{A. Preparasi Adsorben ASP}

Sekam padi dicuci terlebih dahulu dengan akuades untuk menghilangkan zat-zat pengotor anorganik. Secara fisik, sekam padi yang telah dicuci berubah warna menjadi lebih gelap dan lebih keras akibat adanya air yang terserap di dalamnya (Gambar 1). Untuk menghilangkan kadar airnya, sekam 
padi dimasukkan ke dalam oven selama 2 sehingga hanya sekam padi kering yang jam pada suhu $\pm 105^{\circ} \mathrm{C}$ (Kermani, 2006) tersisa. Sekam padi yang telah dikeringkan hingga beratnya konstan. Pada suhu ini, dalam oven menjadi lebih kasar dan ringan diharapkan air dapat menguap seluruhnya, akibat pemanasan.

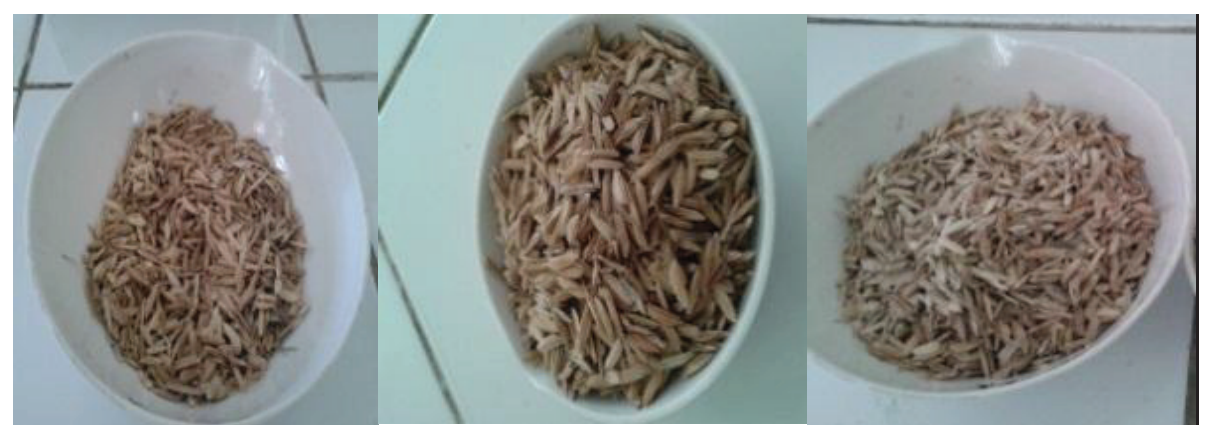

(a)

(b)

(c)

Gambar 1. Sekam padi: (a) sebelum dicuci; (b) setelah dicuci; (c) setelah dioven

Adapun kadar abu sekam padi dari masing-masing temperatur pembakaran diperoleh seperti pada Tabel 1.

Tabel 1. Rendemen hasil pengabuan sekam padi pada variasi temperatur

\begin{tabular}{|c|c|}
\hline Adsorben & Rendemen (\%) \\
\hline ASP-300 & 35,4 \\
\hline ASP-500 & 25,0 \\
\hline ASP-700 & 16,5 \\
\hline
\end{tabular}

Perbedaan temperatur pembakaran sehingga bobotnya menjadi lebih ringan dan memberikan kadar abu yang berbeda-beda. senyawa-senyawa organik terbakar atau Kadar abu dapat menyatakan kandungan hilang membentuk $\mathrm{CO}_{2}$ dan $\mathrm{H}_{2} \mathrm{O}$ dalam mineral yang terkandung di dalam materi bentuk gas. atau biomassa. Berdasarkan hasil pembuatan

Pada suhu pembakaran $300-700^{\circ} \mathrm{C}$, abu, semakin tinggi suhu pengabuan, kadar silika yang diperoleh masih berupa semakin sedikit rendemen abu yang amorf. Bentuk silika dalam abu sekam padi dihasilkannya. Suhu yang tinggi dapat tergantung pada suhu dan waktu pembakaran. menghancurkan struktur suatu materi, Suhu pembakaran ideal untuk membentuk 
silika amorf terjadi pada pembakaran 600$700^{\circ} \mathrm{C}$ (Zemke, 2009). Di atas suhu $700^{\circ} \mathrm{C}$ dan pada waktu yang lama akan menghasilkan silika kristal dalam fasa kristobalit atau tridimit.

\section{B. Karakterisasi Adsorben ASP}

Karakter adsorben dilihat secara kimiawi dari komposisi senyawa silika yang terkandung di dalamnya yang ditentukan dengan metode analisis gravimetri. Teknik analisis gravimetri pada penentuan kadar Silika adalah penguapan atau pengeringan yang berprinsip pada penguapan analit, penimbangan matriks, dan penentuan bagian yang hilang.

Tabel 2. Kadar silika pada variasi temperatur pengabuan sekam padi

\begin{tabular}{|c|c|}
\hline Adsorben & Kadar Silika (\%) \\
\hline ASP-300 & 43,12 \\
\hline ASP-500 & 72,12 \\
\hline ASP-700 & 87,7 \\
\hline
\end{tabular}

Kadar silika pada abu sekam padi dari ketiga variasi temperatur pengabuan berada di bawah 90\% (lihat Tabel 2). Hal ini dimungkinkan bahwa sekam padi yang dianalisis telah terkontaminasi oleh zat pengotor lain.

Penentuan silika dengan gravimetri diawali dengan membasahi abu sekam padi (ASP) terlebih dahulu dengan akuades agar siloksan ( $\mathrm{Si}-\mathrm{O}-\mathrm{Si}$ ) dapat bereaksi dengan asam nitrat dan asam perklorat, sehingga $\mathrm{Si}$ dapat terpisahkan dari Al dan menimalisasi kopresipitasi. Fungsi dari pemanasan adalah untuk mempercepat pemisahan oksida-oksida yang masih terjebak dalam proses pertumbuhan kristal silika, ditandai dengan keluarnya uap putih.Pemanasan berikutnya setelah penambahan akuades berfungsi untuk melarutkan garam-garam yang terbentuk. Garam-garam yang terbentuk disaring menggunakan kertas saring Whatman no. 41 yang bebas abu yang biasanya digunakan dalam analisis gravimetri. Filtrat yang diperoleh bercampur dengan garam-garam pengotor yang larut di dalamnya, sehingga filtrat yang dihasilkan tidak diperlukan. Residu dan kertas saring yang telah diketahui massanya, dipijarkan di dalam furnace pada suhu $1000^{\circ} \mathrm{C}$ selama 30 menit untuk mengoptimalkan pengendapan (merubah endapan ke dalam bentuk senyawa baru yaitu silika). Kemudian, residu didinginkan di 
dalam desikator selama 20 menit agar kandungan uap air hilang diperoleh berat endapat yang stabil yang dicatat sebagai berat A (sebelum proses penambahan HF).

Endapan yang diperoleh dimasukkan ke dalam krus teflon karena agar wadah endapan tidak larut dengan HF yang akan ditambahkan. Bahan-bahan kaca dapat larut dengan asam florida. Kemudian endapan dilarutkan dengan asam florida dan asam sulfat. Setelah dilarutkan dengan asam HF dan $\mathrm{H}_{2} \mathrm{SO}_{4}$, larutan diuapkan hingga kering di atas penangas pasir. Pasir memiliki daya tahan panas yang lebih tinggi daripada air, sehingga digunakan sebagai penangas dalam penguapan silika yang memiliki titih didih lebih tinggi daripada air, yakni $2230^{\circ} \mathrm{C}$.

Asam florida adalah asam yang mampu melarutkan dan reaktif terhadap silika paling baik di antara pelarut asam lainnya. Penambahan HF dapat mengubah Silika menjadi bentuk $\mathrm{SiF}_{4}$ dan menguap (Bakri, 2008). Adapun reaksi yang terjadi yaitu:

$\mathrm{SiO}_{2(\mathrm{~s})}+6 \mathrm{HF}_{(\mathrm{aq})} \rightarrow \mathrm{H}_{2}\left(\mathrm{SiF}_{6}\right)_{(\mathrm{aq})}+2 \mathrm{H}_{2} \mathrm{O}_{(\mathrm{aq})}$ $\mathrm{H}_{2}\left(\mathrm{SiF}_{6}\right)_{(\mathrm{aq})} \rightarrow \mathrm{SiF}_{4(\mathrm{aq})}+2 \mathrm{HF}_{(\mathrm{aq})}$

Larutan Silika yang telah mengering dipijarkan di dalam furnace pada suhu $1000^{\circ} \mathrm{C}$ selama 2 menit untuk menghitung senyawa yang hilang, yaitu silika. Setelah dipijarkan, residu dimasukkan ke dalam desikator selama 20 menit agar suhunya stabil dan kandungan uap air hilang, kemudian ditimbang dan dicatat sebagai berat endapan B (setelah proses penambahan HF).

Zat pengotor lain yang tersisa di dalam endapan, seperti alumina, berubaha menjadi bentuk floridanya. Setelah bereaksi dengan $\mathrm{H}_{2} \mathrm{SO}_{4}$ pada suhu $1000^{\circ} \mathrm{C}$, pengotor tersebut berubah kembali menjadibentuk oksidanya (Bakri, 2008). Reaksi yang terjadi:

$$
\begin{aligned}
& 2 \mathrm{Al}_{2} \mathrm{O}_{3(\mathrm{~s})}+6 \mathrm{HF}_{(\mathrm{aq})} \rightarrow 2 \mathrm{AlF}_{3(\mathrm{aq})}+3 \mathrm{H}_{2} \mathrm{O}_{(\mathrm{aq})} \\
& 2 \mathrm{AlF}_{3(\mathrm{aq})}+3 \mathrm{H}_{2} \mathrm{SO}_{4} \rightarrow \mathrm{Al}_{2}\left(\mathrm{SO}_{4}\right)_{3(\mathrm{aq})}+6 \mathrm{HF}_{(\mathrm{aq})} \\
& \mathrm{Al}_{2}\left(\mathrm{SO}_{4}\right)_{3(\mathrm{aq})} \rightarrow \mathrm{Al}_{2} \mathrm{O}_{3(\mathrm{~s})}+\mathrm{SO}_{3(\mathrm{aq})}
\end{aligned}
$$

Pengurangan jumlah endapan setelah penambahan HF dengan sebelum penambahan HF merupakan berat silika.Kadar silika dalam ASP dihitung dengan membagi berat silika dalam berat sampel yang dianalisis dalam persen (1/100).

\section{Penyerapan ASP terhadap MB}

Kemampuan adsorbsi yang tinggi mengindikasikan bahwa adsorben tersebut dapat menyerap adsorbat dengan sangat baik karena adsorbat yang diserapnya sangat banyak. Menurut Foodan Hameed (2009), kapasitas adsorbsi adsorben abu sekam padi terhadap pewarna metilen biru dalam fasa cair adalah $690 \mathrm{mg} / \mathrm{g}$. 
Tabel 3. Kapasitas adsorbsi dari tiga varian abu sekam padi

\begin{tabular}{|c|c|}
\hline Adsorben & Adsorbtivitas (mg/g) \\
\hline ASP-300 & 1,1616 \\
\hline ASP-500 & 0,7507 \\
\hline ASP-700 & 0,4128 \\
\hline
\end{tabular}

Secara fisik, metilen biru yang telah diadsorbsi dengan abu sekam padi memberikan perubahan warna atau mengalami dekolorisasi (lihat Tabel 4 dan Gambar 2).
Penentuan adsorbansi ASP terhadap MB diawali dengan penentuan panjang gelombang maksimum karena alat yang digunakan memiliki ketelitian tersendiri dalam pembacaan serapan MB.

Tabel 4. Kejernihan warna metilen biru setelah adsorbsi

\begin{tabular}{|c|c|c|}
\hline Adsorben & Warna Sebelum Adsorbsi & Warna Setelah Adsorbsi $^{\text { }}$ \\
\hline ASP-300 & Biru tua & Bening $^{1}$ \\
\hline ASP-500 & Biru tua & Bening $^{2}$ \\
\hline ASP-700 & Biru tua & Bening $^{3}$ \\
\hline
\end{tabular}

Keterangan: urutan kejernihan $1>2>3$

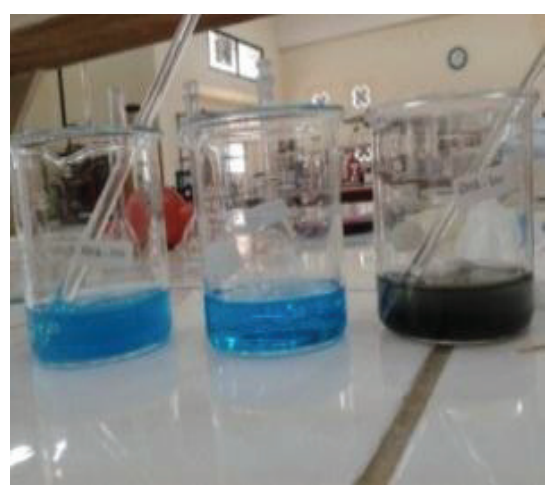

(a)

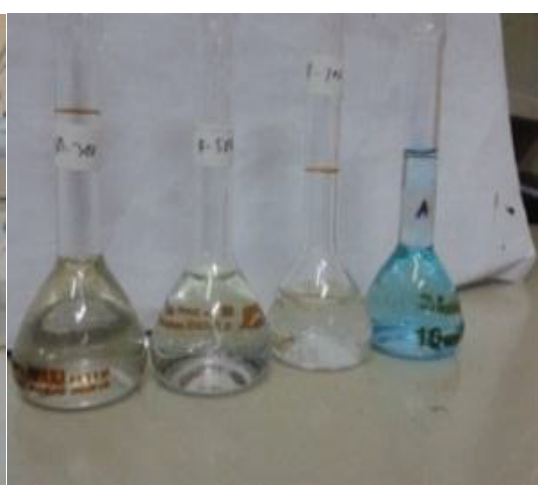

(b)

Gambar 2. (a): Saat adsorbsi metilen biru (dari kiri ke kanan adalah ASP-500, ASP-700, ASP-300); (b): Setelah adsorbsi (dari kiri ke kanan adalah ASP-300, ASP-500, ASP-700, standar) 
Panjang gelombang maksimum serapan MB yang dianalisis berada pada $664 \mathrm{~nm}$ dengan nilai absorbansi 0,934 (lihat Gambar 3).

Panjang gelombang maksimum 664 nm seterusnya digunakan untuk panjang gelombang pada penentuan serapan sampel. Proses adsorbsi oleh adsorben ASP terhadap zat warna metilen biru dipengaruhi oleh waktu kontak dan pH. Proses adsorbsi dalam penelitian ini dilakukan dengan perlakuan yang optimum, dengan $\mathrm{pH} 3$ dan waktu kontak atau pengocokan selama 10 menit. Kondisi $\mathrm{pH}$ yang lebih tinggi dari 3 membuat metilen biru akan membentuk garam yang dapat mengionisasi gugus pergi $\mathrm{Cl}^{-}$dari metilen biru seperti pada Gambar 4.

\section{Panjang Gelombang Maksimum}

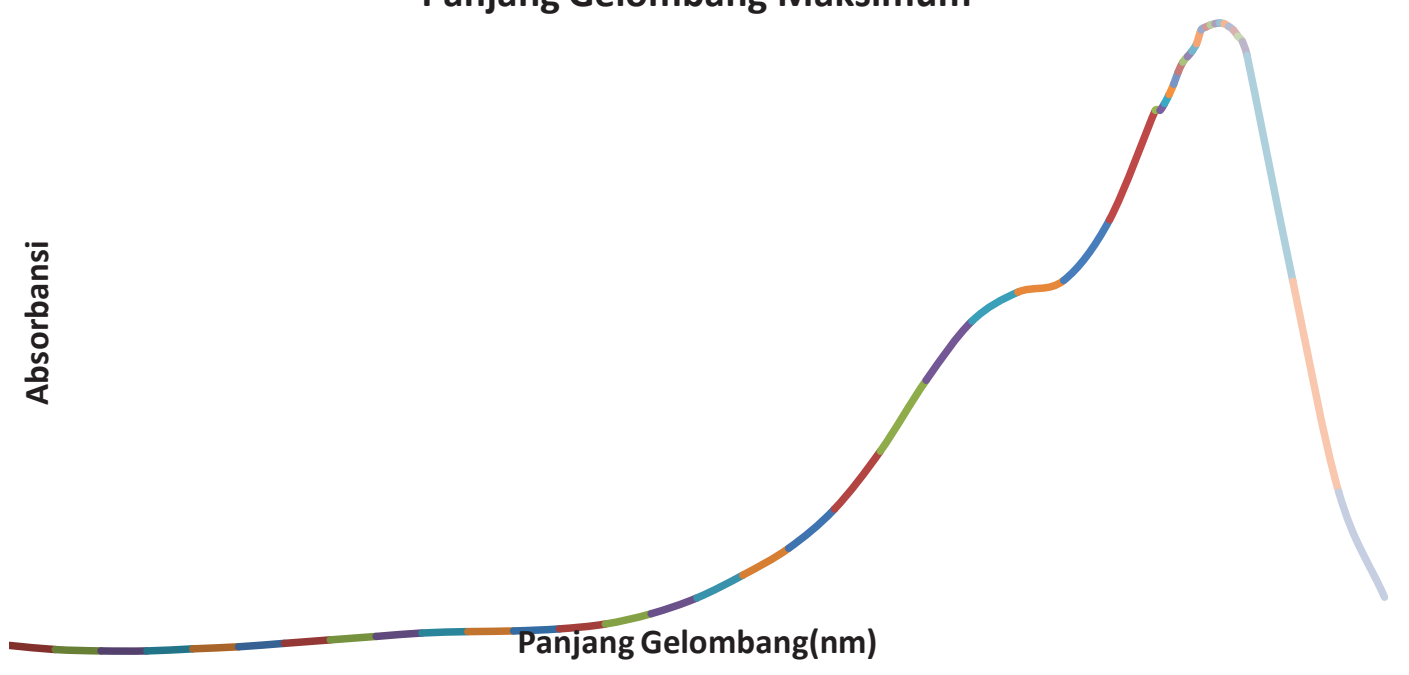

Gambar 3. Penentuan panjang gelombang maksimum

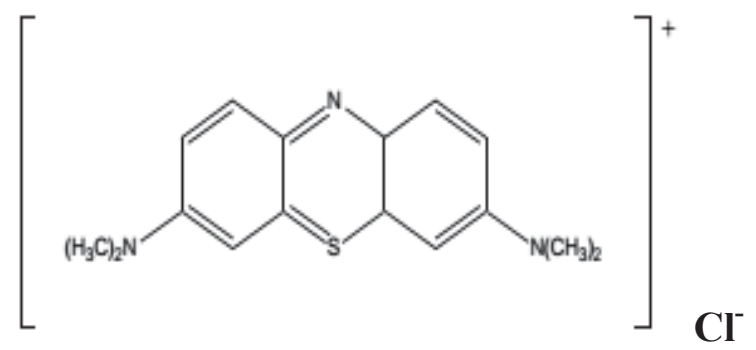

Gambar 4. Struktur ion metilen biru 
Sementara itu, pada waktu yang sama ion $\mathrm{OH}^{-}$dari ASP akan hadir dan menghambat proses adsorbsi terhadap metilen biru yang berada dalam bentuk ion. Kejadian ini mengakibatkan terjadinya repulsi karena muatan di sekitar permukaan pori-pori adsorben sama dengan muatan pada metilen biru. Akhirnya, metilen biru tidak dapat masuk (terserap) ke dalam pori-pori ASP.

Sebaliknya pada $\mathrm{pH}$ rendah, banyaknya ion $\mathrm{OH}^{-}$dari gugus aktif siloksan dan silanol dari ASP akan mengelilingi permukaan metilen biru dan dapat terikat pada gugus $\mathrm{N}$ yang ada pada metilen biru. Keadaan ini mampu meningkatkan interaksi tarik-menarik antara adsorben ASP dengan metilen biru.

\section{Karakterisasi Minyak Nilam} Sebelum dan Sesudah Adsorbsi

\section{Pengujian Warna}

Pengamatan warna langsung dengan kontak mata pada jarak $30 \mathrm{~cm}$. Warna minyak nilam sesudah adsorbsi telah memenuhi standar mutu SNI tahun 2006, dengan warna pengamatan kuning kecoklatan (Gambar 5). Hal ini menunjukkan bahwa adanya zat pengotor yang terserap oleh ASP hingga warna minyak nilam lebih jernih. Adsorben ASP-700 memberikan warna minyak nilam setelah adsorbsi lebih cerah.

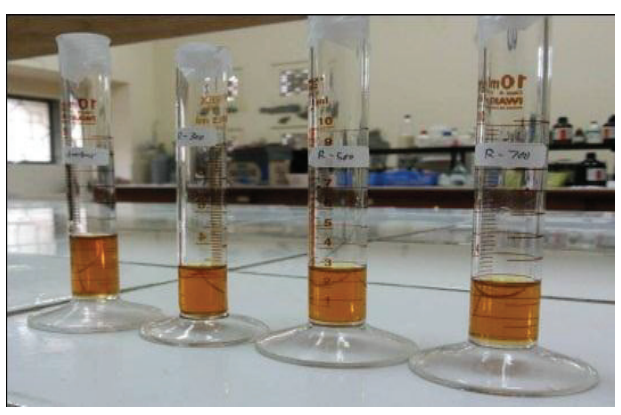

Gambar 5. Minyak nilam sebelum dan sesudah pemurnian (dari kiri ke kanan yaitu awal, ASP-300, ASP-500, dan ASP-700)

\section{Penentuan Bobot Jenis}

Prinsip dari penentuan bobot jenis yang dilakukan adalah sebagai perbandingan antara berat jenis air terhadap berat jenis minyak. Pengukuran berat jenis air dan minyak dilakukan pada suhu yang sama yakni $25^{\circ} \mathrm{C}$. Bobot jenis minyak nilam sebelum dan sesudah penjerapan telah 
memenuhi standar SNI, dimana ASP-700 berhasil menghilangkan pengotor paling banyak terlihat dari bobot jenis minyak nilam yang paling rendah (lihat Tabel 5).

Penentuan Indeks Bias
Prinsip pengukuran indeks bias ini adalah mengukur secara langsung sudut bias minyak pada kondisi suhu yang tetap. Alat yang digunakan untuk mengukur indeks bias yaitu refraktometer.

Tabel 5. Sifat fisika-kimia minyak nilam hasil pemurnian

\begin{tabular}{|c|c|c|c|c|c|}
\hline \multirow{2}{*}{ Parameter } & \multicolumn{4}{|c|}{ Hasil Pengamatan } & \multirow{2}{*}{ SNI } \\
\cline { 2 - 5 } Warna & Awal & ASP-300 & ASP-500 & ASP-700 & 06-2385-2006 \\
\hline $\begin{array}{c}\text { Kuning } \\
\text { kecoklatan } \\
\text { Jernih }^{3}\end{array}$ & $\begin{array}{c}\text { Kuning } \\
\text { kecoklatan } \\
\text { jernih }\end{array}$ & $\begin{array}{c}\text { Kuning } \\
\text { kecoklatan } \\
\text { jernih }\end{array}$ & $\begin{array}{c}\text { Kuning } \\
\text { kecoklatan } \\
\text { jernih }^{1}\end{array}$ & $\begin{array}{c}\text { Kuning muda- } \\
\text { coklat } \\
\text { kemerahan }\end{array}$ \\
\hline $\begin{array}{c}\text { Bobot jenis } \\
25^{\circ} \mathrm{C} / 25^{\circ} \mathrm{C}\end{array}$ & 0,996 & 0,973 & 0,970 & 0,967 & $0,950-0,975$ \\
\hline Indeks bias $\left(\mathrm{nD}^{27}\right)$ & 1,508 & 1,507 & 1,507 & 1,507 & $1,507-1,515$ \\
\hline Kadar Fe $(\mathrm{mg} / \mathrm{kg})$ & 75,2632 & 28,7463 & 20,3335 & 13,2413 & Maks. 25 \\
\hline Kadar $\mathrm{Zn}(\mathrm{mg} / \mathrm{kg})$ & 0,0069 & 0,0345 & $-4,6379$ & $-6,3535$ & - \\
\hline
\end{tabular}

Keterangan : $\left.{ }^{*}\right)$ kejernihan $1>2>3$

Pengukuran indeks bias diawali dengan pembersihan kaca objek dengan etanol dan dietil eter agar zat-zat pengotor organik yang tersisa dapat hilang. Etanol bersifat mudah menguap pada suhu kamar sehingga digunakan dalam pembersihan. Setelah minyak nilam diletakkan di atas kaca objek, stereo diatur hingga membentuk bayangan gelap di bagian bawah dan terang di bagian atas berposisi horizontal dengan ukuran masing-masing setengah diameter lingkaran dalam.

Indeks bias minyak nilam sebelum dan sesudah pemurnian (Tabel 5) menunjukkan mutu minyak nilam yang baik. Semua adsorben ASP, baik ASP-300, ASP-500 maupun ASP-700 telah menurunkan indeks bias minyak nilam, yang membuat beberapa zat organik telah hilang, sehingga minyak nilam memiliki kemurnian yang lebih tinggi.

\section{Analisis Kadar Fe dan Zn dengan SSA}

Salah satu sifat kimia minyak nilam dilihat dari kadar logamnya, terutama besi (Fe). Minyak nilam yang baik harus mengandung logam Fe maksimal sebesar 25 $\mathrm{mg} / \mathrm{kg}$ menurut SNI tahun 2006. Sementara itu, BSN (Badan Standardisasi Nasional) belum menetapkan kadar logam Seng ( $\mathrm{Zn}$ ) dalam mutu minyak nilam. Kadar logam Fe 
dalam minyak nilam yang ditampilkan pada Tabel 5 menunjukkan bahwa mutu minyak nilam sebelum adsorbsi dengan ASP belum memenuhi SNI, sebaliknya hanya ASP-500 dan ASP-700 yang memenuhi SNI. Nilai ini menghadirkan penurunan kadar logam dalam minyak nilam setelah adsorbsi dengan adsorben ASP.

Kadar logam Fe dan Zn dalam minyak nilam dianalisis dengan menggunakan Spektrofotometri Serapan Atom (SSA). Prinsip metode SSA adalah berdasarkan pada adsorbsi cahaya oleh suatu atom (Gandjar, 2010). Atom-atom menyerap cahaya pada panjang gelombang tertentu yang tergantung pada sifat unsurnya. Penyerapan energi radiasi oleh atom-atom dalam keadaan dasar inilah yang menjadi ukuran dalam SSA yang disebut absorbansi. Pengujian kadar logam pada minyak nilam sebelum dan sesudah pemurnian dilakukan dengan cara yang sama. Perbedaannya terletak pada adsorbsi saja.

Preparasi minyak nilam dilakukan dengan preprasi kering dalam tanur pada suhu relatif tinggi hingga terbentuk abu. Kemudian dilanjutkan dengan preparasi basah dengan penambahan asam regia $\left(\mathrm{HCl}: \mathrm{HNO}_{3}=3: 1\right)$ untuk memutuskan ikatan antara logam dengan senyawa organiknya dalam minyak nilam, sehingga logam dapat terbaca saat pengujian dengan SSA.
Serapan minyak nilam diukur pada panjang gelombang 248,3 nm untuk pengujian kadar logam Fe dan 213,9 nm untuk logam Zn. Konsentrasi logam Fe dan Zn dihitung dengan metode kurva kalibrasi yaitu dengan memasukkan nilai absorbansinya ke persamaan regresi linier yang dibentuk dari larutan standar Fe dan Zn. Dengan metode kurva standar, kadar Fe dan Zn dalam minyak nilai dapat telah memnuhi standar mutu minya nilam sesuai SNI (lihat Tabel 5).

Peristiwa berkurangnya konsentrasi logam Fe dan $\mathrm{Zn}$ di dalam minyak nilam adalah gejala yang ditimbulkan akibat peristiwa adsorbsi, yang mana sejumlah logam terjerap di permukaan adsorben abu sekam padi. Interaksi antara adsorbat (logam $\mathrm{Fe}$ ) dengan adsorben (Silika ASP) terjadi karena adanya gayavan der Waals dari kedua atom yang bersifat nonpolar. Gaya ini juga disebut dengan gaya dispersi (London Force). Terjadinya fisisorpsi ini berlangsung pada temperatur rendah dengan energi adsorbsi yang dilepaskan sekitar $20 \mathrm{~kJ} / \mathrm{mol}$. Peristiwa ini dapat dijelaskan pada Gambar 6. 


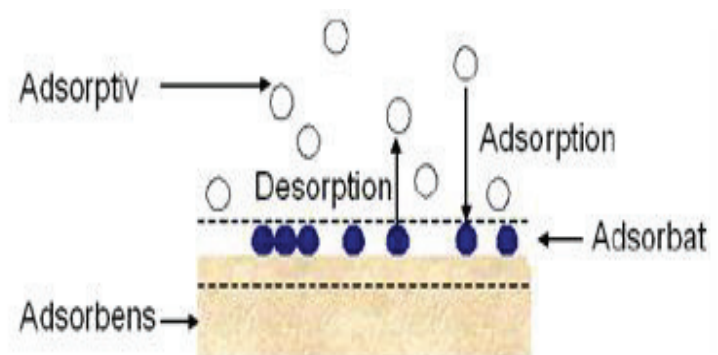

Gambar 6. Proses adsorbsi fisik

Kondisi pirolisis sekam padi menjadi siloksan (Si-O-Si). Aktivitas kedua gugus ini abu sangat mempengaruhi kadar karbon dan dipengaruhi oleh kondisi $\mathrm{pH}$ larutan. Akan silika dalam abu sekam padi. Kondisi tetapi, kemampuan adsorbsi silika tidak pirolisis yang dapat dikontrol yaitu suhu sebanding dengan jumlah gugus aktifnya pembakaran dan waktu pembakaran. pada permukaan, melainkan bergantung pada Semakin tinggi dan semakin lama pirolisis distribusi gugus $-\mathrm{OH}$ tiap unit area adsorben. sekam padi, semakin tinggi pula kadar silika Gugus - $\mathrm{OH}$ membuat permukaan adsorben yang diperoleh. Sebagaimana terlihat pada bersifat polar. Akibatnya, ion logam besi dan Tabel 5, sekam padi yang dibuat pada suhu seng dapat terjerap oleh gugus - OH pada pirolisis $700^{\circ} \mathrm{C}$ memiliki kadar silika yang permukaan dengan menghasilkan pertukaran paling tinggi dan didukung dengan besarnya kation sebagai gejala kemisorpsi. Reaksi diameter pori yang terbentuk. yang terjadi:

Di dalam abu sekam padi terdapat gugus aktif berupa silanol ( $\mathrm{Si}-\mathrm{OH})$ dan

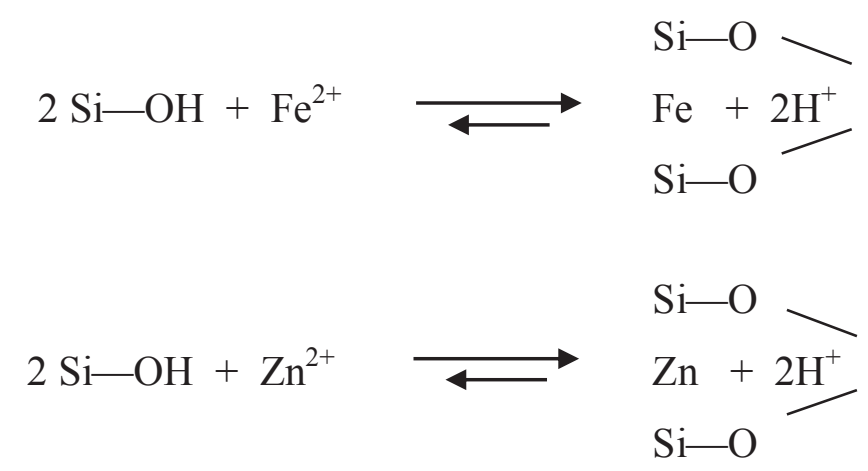

Gambar 7. Reaksi kemisorpsi yang diperkirakan terjadi di dalam permukaan adsorben ASP 
Gugus $-\mathrm{OH}$ di dalam abu sekam padi yang telah hilang unsur karbonnya, terikat oleh atom Silikon yang berjumlah banyak, sehingga senyawa yang mungkin aktif adalah Si-OH. Pembentukan kompleks koordinasi dari antara gugus $-\mathrm{OH}$ dengan ion logam juga dapat dimungkinkan terjadi. Atom Oksigen (O) pada gugus $-\mathrm{OH}$ memiliki pasangan elektron bebas, sementara ion logam Fe dan Zn memiliki orbital d yang kosong. Pasangan elektron bebas dari ligan $\mathrm{OH}$ akan menempati ruang orbital d yang masih kosong dari ion logam Fe dan $\mathrm{Zn}$, sehingga terbentuk suatu senyawa baru yang berikatan kovalen koordinasi.

Kemampuan adsorbsi dari adsorben abu sekam padi dalam menyerap logam Fe dan Zn dalam minyak nilam dapat dinyatakan ke dalam adsorbtivitas. Semakin tinggi adorbtivitasnya, semakin baik adsorben tersebut digunakan karena mampu menyerap adsorbat dalam jumlah banyak.

Berdasarkan perhitungan, adsorbtivitas ASP terhadap logam Fe dan Zn dapat dilihat pada Tabel 6 .

Tabel 6. Adsorbtivitas dan efisiensi adsorbsi ASP terhadap logam Fe dan Zn

\begin{tabular}{|c|c|c|}
\hline \multirow{2}{*}{ Adsorben } & \multicolumn{2}{|c|}{ Adsorbtivitas (mg/g) } \\
\cline { 2 - 3 } & Logam Fe & Logam Zn \\
\hline ASP-300 & 0,465169 & $-0,0000172414$ \\
\hline ASP-500 & 0,549297 & 0,004655172 \\
\hline ASP-700 & 0,620219 & 0,00637069 \\
\hline
\end{tabular}

Abu sekam padi yang dibuat pada suhu pengabuan atau pirolisis $700^{\circ} \mathrm{C}$ memberikan nilai adsorbtivitas paling baik dalam mengadsorbsi logam Fe dan Zn. Hal ini dapat memberikan indikasi bahwa semakin tinggi suhu pirolisis sekam padi menjadi abu sekam padi (ASP), semakin tinggi pula kemampuan adsorbsi nya.

\section{Kesimpulan}

Hasil penelitian memberikan kesimpulan:
1. Temperatur

pembakaran mempengaruhi karakter fisik dan kimia abu sekam padi.Semakin tinggi temperatur pembakarannya, semakin tinggi pula kadar silikanya, namun semakin rendah dan adsorbtivitasnya terhadap metilen biru.

2. Variasi temperatur pengabuan sekam padi juga berpengaruh pada aplikasi penurunan kadar logam Fe dan Zn dalam minyak nilam. Semakin tinggi 
temperatur pengabuan sekam padi, semakin tinggi kapasitas adsorbsinya untuk menjerap logam Fe dan Zn dalam minyak nilam.

\section{Pustaka}

Badan Standardisasi Nasional, 2006, SNI 062385-2006, Minyak Nilam, Jakarta.

Bakri, 2008, Komponen Kimia dan Fisika Abu Sekam Padi Sebagai SCM untuk Pembuatan Komposit Semen, Jurnal Perennial, 5(1) : 9-14.

Foo, K.Y., and Hameed, B.H., 2009, Utilization of Rice Husk Ash as Novel Adsorbent: A Judicious Recycling of The Colloidal Agricultural Waste. Advanced in Colloid and Interface Science, 152 : 39-47.

Nakbanpote, W., Thiravetyan, dan Kalambaheti, C. 2000, Proconcentration of gold by rice husk ash,Mineral. Eng. 13: 391-400.

Omatola, K.M. dan Onojah, A.D, 2009, Elemental analysis of rice husk ash using $\mathrm{x}$-ray fluorescence technique, International Journal of Physical Science. 4(4): 189-193.
Sipahutar, D., 2012, Teknologi Briket Sekam Padi, Balai Pengkajian Teknologi Riau, Riau.

Zemke, N., dan Woods, E., 2009, Rice Husk Ash, California Polytechnic State University, California. 